Article

\title{
The Design and Investigation of Nanocomposites Containing Dimeric Nematogens and Liquid Crystal Gold Nanoparticles with Plasmonic Properties Showing a Nematic-Nematic Phase Transition $\left(\mathbf{N}_{\mathrm{u}}-\mathbf{N}_{\mathrm{x}} / \mathbf{N}_{\mathrm{tb}}\right)$
}

\author{
Maria-Gabriela Tamba, Chih Hao Yu, Bai Jia Tang, Christopher Welch, Alexandra Kohlmeier, \\ Christopher P. Schubert and Georg H. Mehl * \\ Department of Chemistry, University of Hull, Hull, HU6 7RX, UK; \\ E-Mails: gabriela_tamba@yahoo.com (M.-G.T.); dearchyu@ hotmail.com (C.H.Y.); \\ b.tang@2005.hull.ac.uk (B.J.T.); c.welch@hull.ac.uk (C.W.); alex_km@yahoo.de (A.K.); \\ chris.schubert@chem.queensu.ca (C.P.S.) \\ * Author to whom correspondence should be addressed; E-Mail: g.h.mehl@hull.ac.uk; \\ Tel.: +44-1482-465-590; Fax: +44-1482-466-410.
}

Received: 12 March 2014; in revised form: 11 April 2014 / Accepted: 17 April 2014 /

Published: 30 April 2014

\begin{abstract}
The construction of liquid crystal compositions consisting of the dimeric liquid crystal, CB_C9_CB (cyanobiphenyl dimer = 1",9"-bis(4-cyanobiphenyl-4'-yl)nonane), and the range of nematic systems is explored. The materials include a laterally functionalized monomer, which was used to construct a phase diagram with $\mathbf{C B}$ _C9_CB, as well as one laterally linked dimer liquid crystal material and two liquid crystal gold nanoparticle (LC-Au-NPs) systems. For the Au-NP-LCs, the NP diameters were varied between $\sim 3.3 \mathrm{~nm}$ and $10 \mathrm{~nm}$. Stable mixtures that exhibit a nematic-nematic phase transition are reported and were investigated by POM (polarizing optical microscopy), DSC (differential scanning calorimetry) and X-ray diffraction studies.
\end{abstract}

Keywords: nanocomposite; liquid crystal; nematic-nematic; phase diagram; dimer; siloxane; mixtures; nanoparticles; plasmonic; gold 


\section{Introduction}

The investigation of materials that show nematic-nematic transitions has increased considerably over the last few years since the first report on such a phase behaviour in dimeric liquid crystals [1]. This is due to the scientific novelty of a new nematic phase, different in organisation to that of the classical uniaxial nematic $(\mathrm{Nu})$ phase. Additionally, there is considerable interest in the structure of this low temperature nematic phase, as its mode of assembly is not yet fully understood. Hence, it has been identified, rather cautiously, as $\mathrm{N}_{\mathrm{x}}$, as a twist-bent nematic phase, $\mathrm{N}_{\mathrm{tb}}$, or as a heliconical nematic phase [2-10]. These issues of phase assignment still need to be clarified, but they raise the more general question of whether a number of different thermotropic nematic phases, positioned below the classical $\mathrm{N}$ phase, do exist in organic or inorganic materials [11-13]. Beyond the interest in the fundamental issues of phase structure, the observation that the low temperature nematic phase in dimers, which in this contribution is termed $\mathrm{N}_{\mathrm{x}}$, simply because its structure has not yet been fully clarified, is characterized by the spontaneous formation of chiral domains. This is of technological relevance, as this property can, in principle, be used to either stabilize or to enhance chirality in already chiral systems, such as TGB (twist grain boundary) arrays, blue phases or to induce chirality in plasmonic metal nanoparticle systems [14]. Here, chirality promises a wide range of novel optical effects $[15,16]$. Moreover, these LC nanoparticle (NPs) systems are potentially extremely interesting for LC applications, as it has been shown that nanoparticles dispersed in liquid crystals can result in enhanced switching behaviour. It has been reported that electro-optical switching in the microsecond regime is possible in the $\mathrm{N}_{\mathrm{x}}$ phase [9]. The first step to realize such advantageous properties is to explore the miscibility of metal nanoparticles in dimeric systems forming the $\mathrm{N}_{\mathrm{x}}$ phase. This is the subject matter of this report. Here, we report the first miscibility study of gold nanoparticles (Au-NPs) in dimers with a nematic-nematic phase transition.

Though a number of NP systems have been functionalized with LC groups in order to enhance their solubility in liquid crystals, the number of calamitic nematogenic systems is very low, and the number of those that exhibit LC behaviour is very small indeed, as discussed in recent reviews [16-19].

\section{Results and Discussion}

As a starting point for the miscibility studies, the dimer, CB_C9_CB (cyanobiphenyl dimer), shown in Figure 1, was used, as the structure of the $\mathrm{N}_{\mathrm{x}}$ phase in this material has been investigated intensively [1,7-10,20]. As LC-Au-NP systems, LC nanoparticle materials reported earlier were used [21-24]. As the LC-Au-NP materials to be investigated employ laterally connected mesogenic groups, different from those that have been shown to exhibit $\mathrm{N}_{\mathrm{x}}$ phase behaviour, the design of the $\mathrm{N}_{\mathrm{x}}$ phase forming composites was approached in a systematic study. In the first step, mixtures with a laterally functionalized nematogen, the liquid crystal, 4'-undecyloxybiphenyl-4-yl-4-octyloxy-2-(pent4-en-1-yloxy) benzoate (1), shown in Figure 1, were performed in order to evaluate the limit of the phase stability in the $\mathrm{N}_{\mathrm{x}}$ phase in such a mesogenic system. For that, a full phase diagram was constructed. A laterally functionalized mesogen was selected, due to the tendency of these systems to show nematic phase behaviour. In the second step, specific compositions of CB_C9_CB with a dimeric system containing siloxane groups (2) were prepared to gain additional knowledge in order to optimize the composition range for the mixtures with the LC-NPs. In the final step, compositions were 
prepared with LC gold particles. Here, liquid crystal Au-NPs were used, which have been reported earlier, using structures, very close to those of the laterally connected mesogen investigated initially. Two systems were explored.

In the first system, the particle size is as about $3.3 \mathrm{~nm}$ (Material 3), and in the second material, the particle diameter is about $10 \mathrm{~nm}$ (Material 4). The chemical structures of the investigated systems are shown in Figure 1.

The addition of the corresponding liquid crystal, 1 (4'-undecyl oxybiphenyl-4-yl 4-octyloxy-2(pent-4-en-1-yloxy) benzoate), which has a positive dielectric anisotropy, $\Delta \varepsilon$, to the dimer, CB_C9_CB, allows the construction of phase diagrams. Though the structures of $\mathbf{1}$ have been discussed earlier as a precursor for mesomorphic silsesquioxanes and carbosilazane dendrimers, detailed LC properties have not yet been discussed [25,26]. Compound 1 exhibits an enantiotropic nematic phase; typical defect textures are shown in Figure 2.

Figure 1. Chemical structures of the materials investigated. CB_C9_CB, cyanobiphenyl dimer.
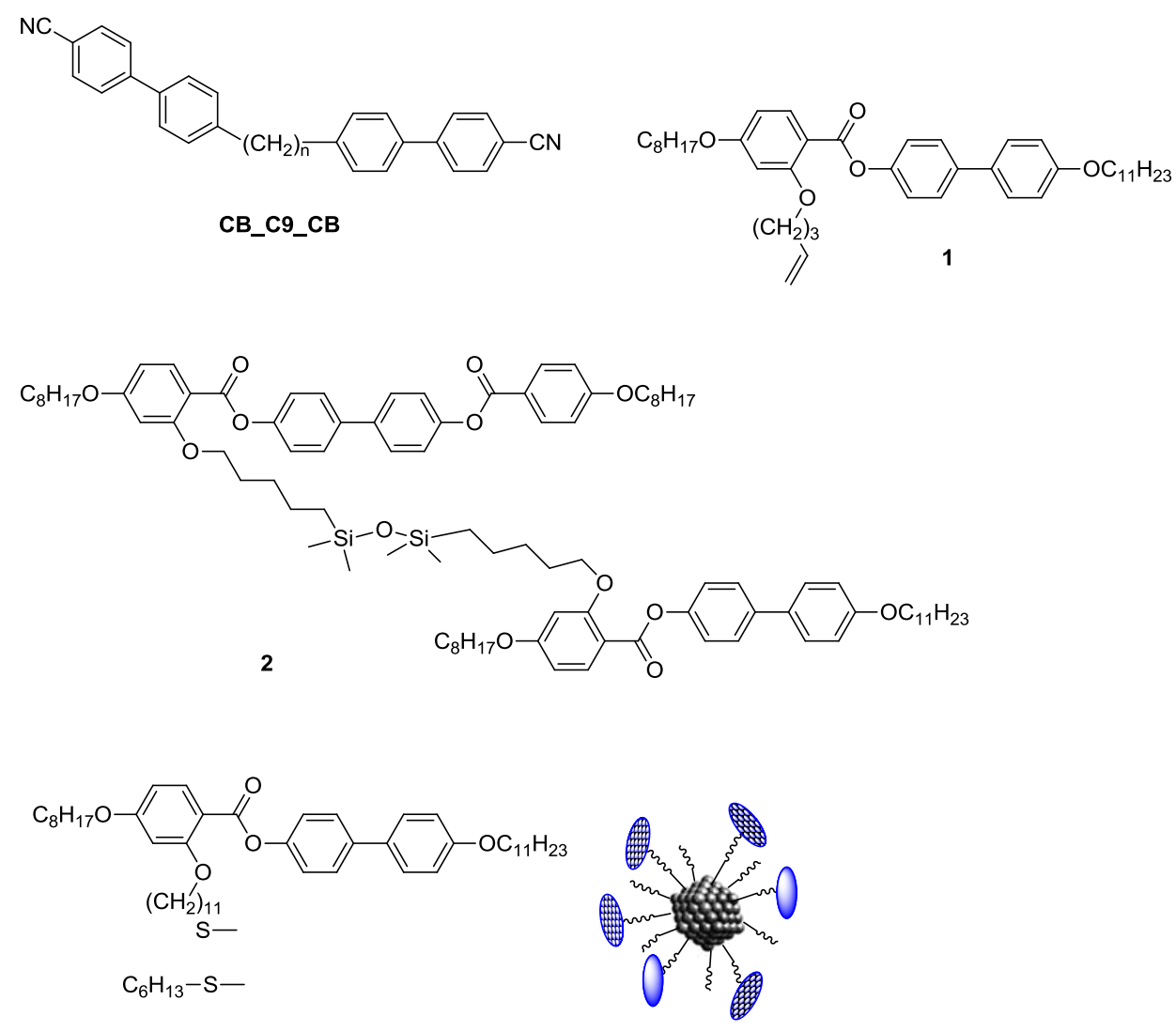

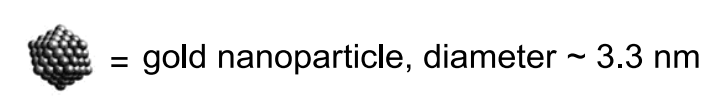
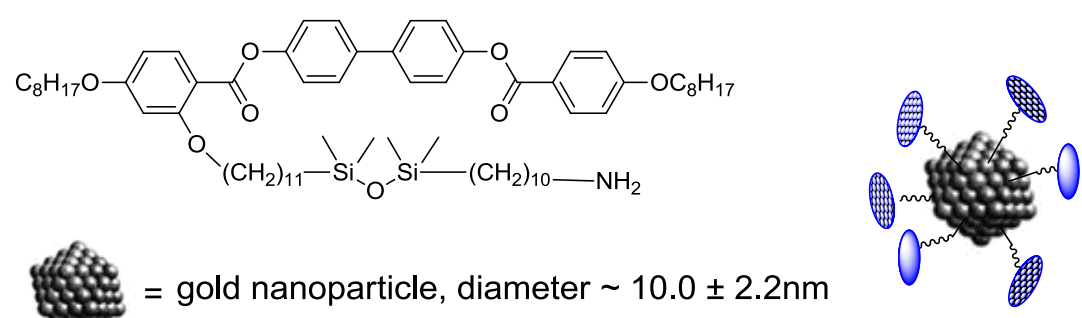
Figure 2. Textures of the nematic phase of 1 between untreated glasses observed between crossed polarizers. (a) $\mathrm{N}$ phase at $25{ }^{\circ} \mathrm{C}$; (b) $\mathrm{N}$ phase at $50{ }^{\circ} \mathrm{C}$.

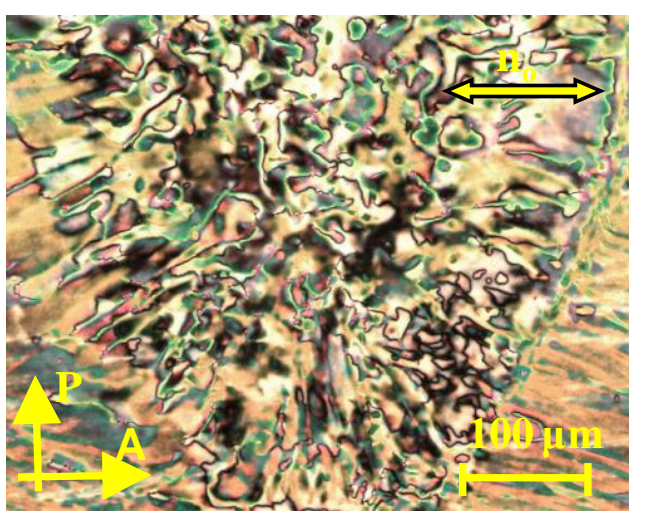

(a)

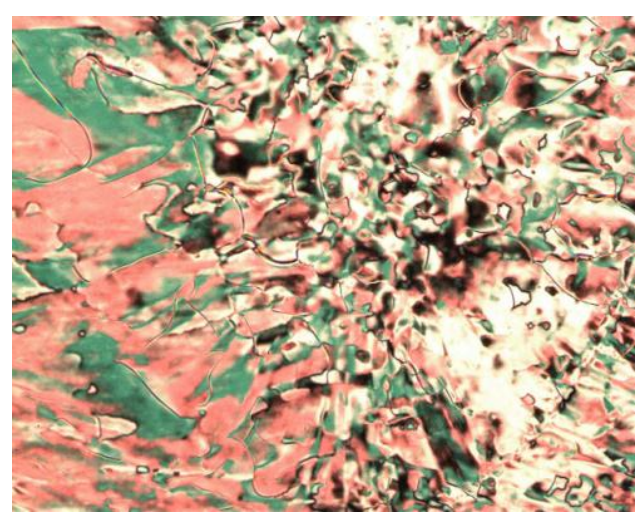

(b)

DSC measurements were conducted at varying heating and cooling rates on samples of Compound 1. The transition temperatures and the corresponding enthalpy values of Compound $\mathbf{1}$ taken from the heating and cooling DSC scan $(10 \mathrm{~K} / \mathrm{min}$, see Figure 3$)$ are given below.

Figure 3. DSC studies $(10 \mathrm{~K} / \mathrm{min})$ of Compound 1; values are taken from the first heating and cooling scans. Cr 54.5 (71.14) N 73.3 (2.39) Iso $\left({ }^{\circ} \mathrm{C}\right)$; Iso $71.8(-2.59) \mathrm{N} 2.06(-1.84)$ $\mathrm{X}-24.6(-6.78) \mathrm{Cr}\left({ }^{\circ} \mathrm{C}\right)$; the numbers in brackets are the transition enthalpies in $\mathrm{J} \cdot \mathrm{g}^{-1}$.

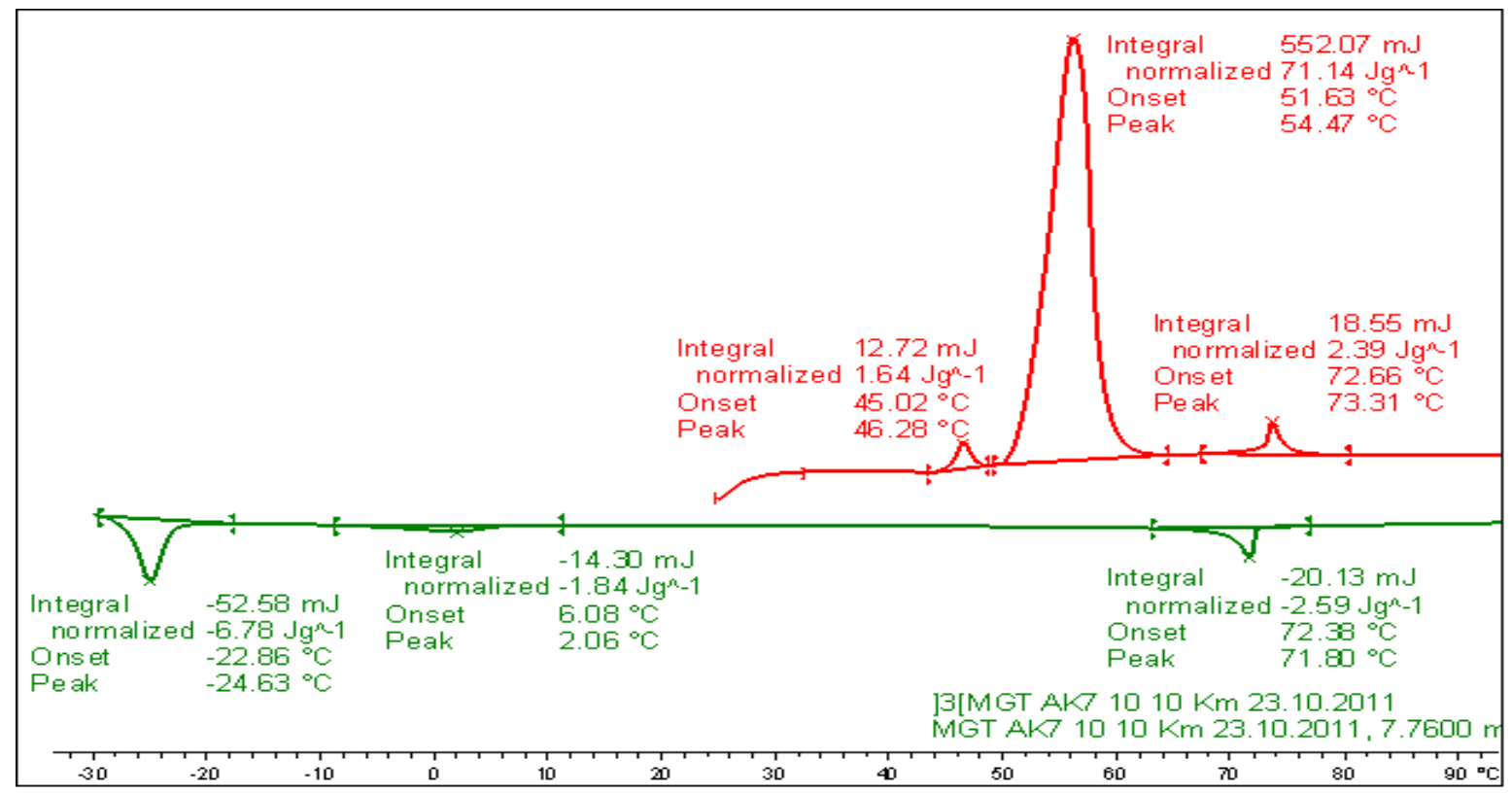

A systematic investigation of the binary mixtures $(\mathrm{w} / \mathrm{w})$ of Material $\mathbf{1}$ with positive dielectric anisotropy with the cyanobiphenyl dimer, CB_C9_CB (5\%-50\% (w/w)), was carried out. All binary mixtures exhibit liquid crystalline behaviour. The mesophase types and the transition temperatures for these mixtures are given in Table 1. All compounds exhibit nematic phases. The mesophases of the mixtures were characterized by their optical textures, calorimetric studies and by X-ray investigations. No additional layer-structured mesophases are induced in the mixed phase region of this binary systems, i.e., only nematic phases could be found. Remarkably, for the system, CB_C9_CB, more 
than $40 \%$ (w/w) of 1 can be added before the $\mathrm{N}_{\mathrm{X}}$ phase is lost (see Figure 4). However, it is noted that the $\mathrm{N}_{\mathrm{x}}$ phase stability is strongly reduced upon adding 1, i.e., for the system with $30 \%(\mathrm{w} / \mathrm{w})$ of $\mathbf{1}$ in CB_C9_CB (MGTP201), a reduction of the transition temperature of the high-temperature $\mathrm{N}$ phase to the low-temperature $\mathrm{N}_{\mathrm{x}}$ phase of about $54{ }^{\circ} \mathrm{C}$ could be found. In other words, the nematic $\mathrm{N}_{\mathrm{X}}$ phase transition occurs on cooling at $62.1{ }^{\circ} \mathrm{C}$. Moreover, the stability of the enantiotropic (that is thermodynamically stable) $\mathrm{N}_{\mathrm{x}}$ phase is lost upon adding between $5 \%(\mathrm{w} / \mathrm{w})$ to $10 \%(\mathrm{w} / \mathrm{w})$ of the monomeric Compound 1.

Table 1. Transition temperatures of the binary mixtures (w/w) of $\mathbf{1}$ with dimer CB_C9_CB, taken from the first DSC heating and cooling scans $\left(10 \mathrm{~K} \cdot \mathrm{min}^{-1}\right)$. $\mathrm{Cr}=$ Crystallie; $\mathrm{N}=$ Nematic $; \mathrm{Nx}=$ Nematic $(\mathrm{x}$ or tb); Iso = isotropic liquid.

\begin{tabular}{|c|c|c|c|}
\hline Binary mixtures & $\begin{array}{c}1 \\
\%(w / w)\end{array}$ & $\begin{array}{c}\text { CB_C9_CB } \\
\%(w / w)\end{array}$ & $\begin{array}{c}\text { Transition temperatures } \\
\qquad\left({ }^{\circ} \mathbf{C}\right)\end{array}$ \\
\hline CB_C9_CB & 0 & 100 & 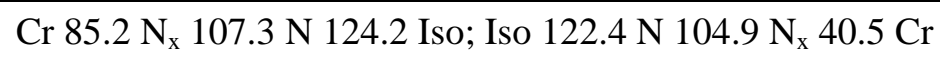 \\
\hline MGTP205 & 5 & 95 & Cr $69.9 \mathrm{~N}_{\mathrm{X}} 95.8 \mathrm{~N} 112.8 \mathrm{Iso}$; Iso $111.3 \mathrm{~N} 92.9 \mathrm{~N}_{\mathrm{X}} 35.3 \mathrm{Cr}$ \\
\hline MGTP204 & 10 & 90 & Cr 85.8 N 108.5 Iso; Iso 107.2 N $86.7 \mathrm{~N}_{\mathrm{X}} 31.1 \mathrm{Cr}$ \\
\hline MGTP200 & 15 & 85 & $\mathrm{Cr} 83.7 \mathrm{~N} 105.2$ Iso; Iso $104.5 \mathrm{~N} 77.8 \mathrm{~N}_{\mathrm{X}} 31.1 \mathrm{Cr}$ \\
\hline MGTP206 & 20 & 80 & Cr 85.2 N 101.1 Iso; Iso 97.2 N $72.7 \mathrm{~N}_{\mathrm{X}} 35.3 \mathrm{Cr}$ \\
\hline MGTP207 & 25 & 75 & $\mathrm{Cr} 84.7$ N 96.1 Iso; Iso $90.9 \mathrm{~N} 70.0 \mathrm{~N}_{\mathrm{X}} 29.9 \mathrm{Cr}$ \\
\hline MGTP201 & 30 & 70 & Cr 69.6 N 90.9 Iso; Iso 86.5 N $62.1 \mathrm{~N}_{\mathrm{X}} 34.2 \mathrm{Cr}$ \\
\hline MGTP202 & 40 & 60 & Cr $68.4 \mathrm{~N} 83.8$ Iso; Iso $80.3 \mathrm{~N} 51.4 \mathrm{~N}_{\mathrm{X}} 34.3 \mathrm{Cr}$ \\
\hline MGTP203 & 50 & 50 & Cr 66.5 N 78.7 Iso; Iso 74.6 N 31.7 Cr \\
\hline 1 & 100 & 0 & Cr 54.5 N 73.3 Iso; Iso 71.8 N 2.06 X -24.6 Cr \\
\hline
\end{tabular}

Figure 4. Transition temperatures of the binary mixtures of dimer CB_C9_CB in 1, taken from the first DSC heating and cooling scans $\left(10 \mathrm{~K} \cdot \mathrm{min}^{-1}\right)$; the phase diagram of the transition temperatures of these mixtures, taken from the first DSC (a) heating scans $\left(10 \mathrm{~K} \cdot \mathrm{min}^{-1}\right)$ and $(\mathbf{b})$ cooling scans $\left(10 \mathrm{~K} \cdot \mathrm{min}^{-1}\right)$.
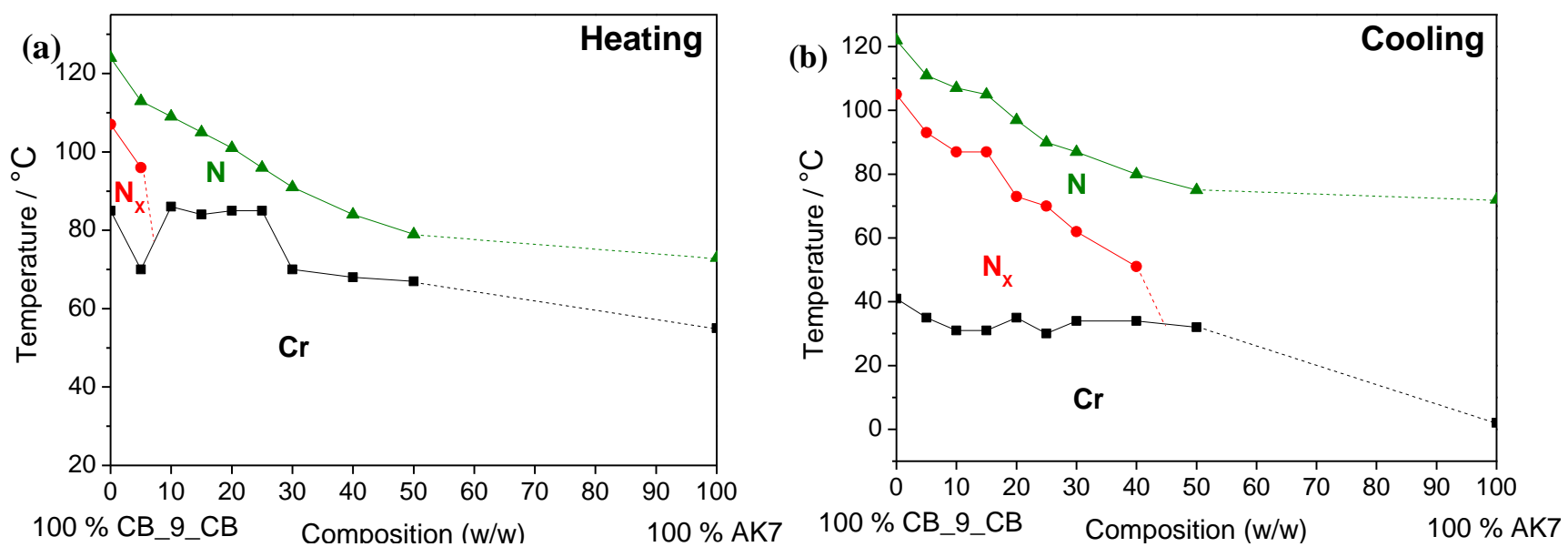

As a representative example the mesophase behaviour of the binary mixture, MGTP201, with 30\% (w/w) 1 in CB_C9_CB will be described in more detail. The POM studies and the calorimetric investigations evidenced the existence of an $\mathrm{N}-\mathrm{N}_{\mathrm{x}}$ phase sequence with textural and structural features similar to the pure cyanobiphenyl dimer, CB_C9_CB. 
The high-temperature phase could be easily identified as a nematic phase by its characteristic texture. At the phase transition to the $\mathrm{N}_{X}$ phase, a fine structured rope texture or fan-like texture develops, as shown in Figure 5a,b. The sheared texture contains non-specific features with homeotropically oriented regions and some oily streaks, as shown in Figure 5c.

Figure 5. Textures of the MGTP201 (30\% (w/w) 1 in 70\% CB_C9_CB) between untreated glasses observed in the same region on cooling between crossed polarizers: (a) schlieren texture in the high-temperature nematic $\mathrm{N}$ phase at $85^{\circ} \mathrm{C}$; (b) fan-like texture accompanied by rope texture developing in the low-temperature $\mathrm{N}_{\mathrm{x}}$ phase at $48{ }^{\circ} \mathrm{C}$ and (c) sheared texture of the low-temperature $\mathrm{N}_{\mathrm{x}}$ phase at $48^{\circ} \mathrm{C}$.

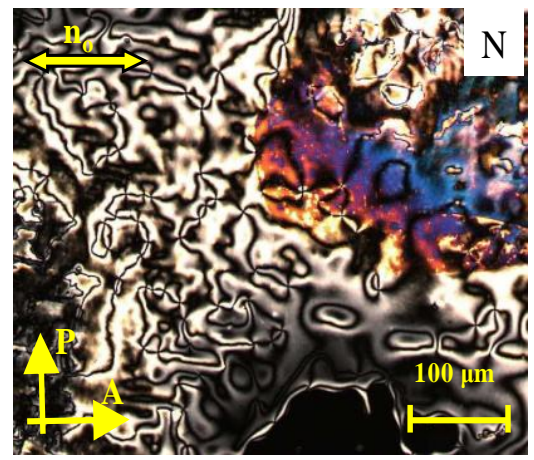

(a)

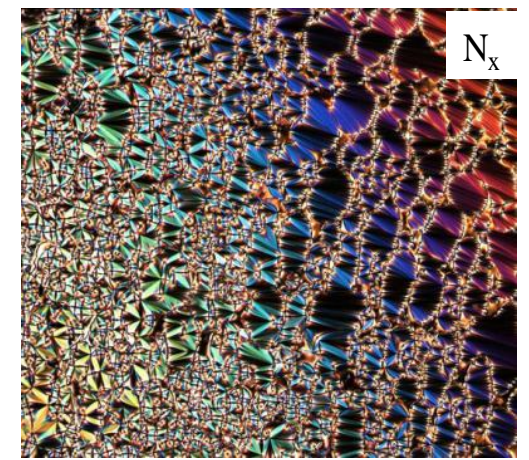

(b)

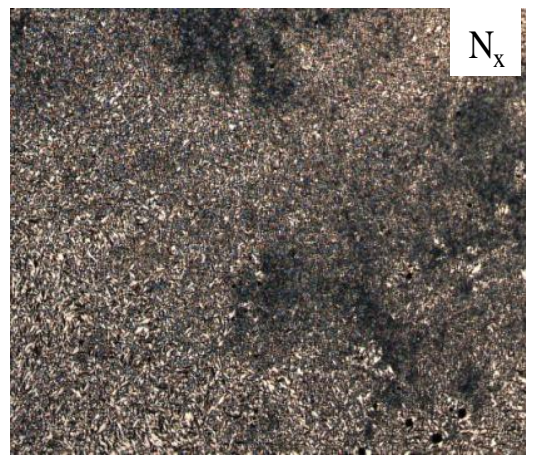

(c)

DSC measurements were conducted at different heating and cooling rates on samples of the binary mixture, MGTP201, consisting of a mixture of 30\% (w/w) 1 in CB_C9_CB. The transition temperatures and the corresponding enthalpy values of the compound MGTP201 taken from the heating and cooling DSC scans recorded at $10 \mathrm{~K} / \mathrm{min}$ (see Figure 6) are given below.

$\mathrm{X}$-ray measurements were performed whilst applying a magnetic field of about $0.5 \mathrm{~T}$ to orient samples of the composition, MGTP201. The results confirm the presence of two nematic phases. The $\mathrm{X}$-ray patterns in the high-temperature nematic state show the known features of the XRD patterns of the nematic phases of the pure cyanobiphenyl dimer, i.e., diffuse crescent-like scattering on the meridian in the small angle region, parallel to the orienting magnetic field, and diffuse crescent-like scattering on the equator in the wide angle region. The diffractograms collected at $77{ }^{\circ} \mathrm{C}$ are shown in Figure 7a,b. Similar to the pure cyanobiphenyl dimer, this pattern does not change significantly at the phase transition to the low-temperature $\mathrm{N}_{\mathrm{x}}$ phase recorded at $50{ }^{\circ} \mathrm{C}$ and shown in Figure $7 \mathrm{c}$,d. There is no indication of a transition to a smectic phase, even though the textural features, such as the fan-shaped texture and or polygonal textures, would suggest, initially, the formation of a smectic-like structure.

It is noted that an addition of 15\%-20\% (w/w) of 1 to CB_C9_CB results in a decrease of the isotropisation temperature by $\sim 20-24{ }^{\circ} \mathrm{C}$, when compared to pure CB_C9_CB.

Based on these successful miscibility studies with a monomer, the work was extended to the dimeric system, $\mathbf{2}$, which is characterized by a very wide nematic range and by having features, such as the central siloxane group, that are present in one of the to be investigated LC gold nanoparticle systems. Compound $\mathbf{2}$ is a dimeric non-symmetric system, whose synthesis has been reported earlier [27]. Material 2 exhibits a wide enantiotropic nematic phase; a typical POM texture is shown in 
Figure 8 . The nematic phase stability of 2 ranges on heating form -8.8 to $107.6{ }^{\circ} \mathrm{C}$. The material was synthesized according to a reported method, and the results of the investigations of the LC phase behaviour are shown below [27].

Figure 6. DSC studies (10 K/min) of the binary mixture, MGTP201 (30\% (w/w) 1 in 70\% (w/w) CB_C9_CB); the values are taken from the second heating and cooling scans. Cr 69.6 (33.05) N 90.9 (1.46) Iso; Iso 86.5 (-2.54) N 62.1 $\mathrm{N}_{\mathrm{x}}(-1.86) 34.2(-23.73)$ $\mathrm{Cr}\left({ }^{\circ} \mathrm{C}\right)$; the numbers in brackets are the transition enthalpies in $\mathrm{J} \cdot \mathrm{g}^{-1}$.

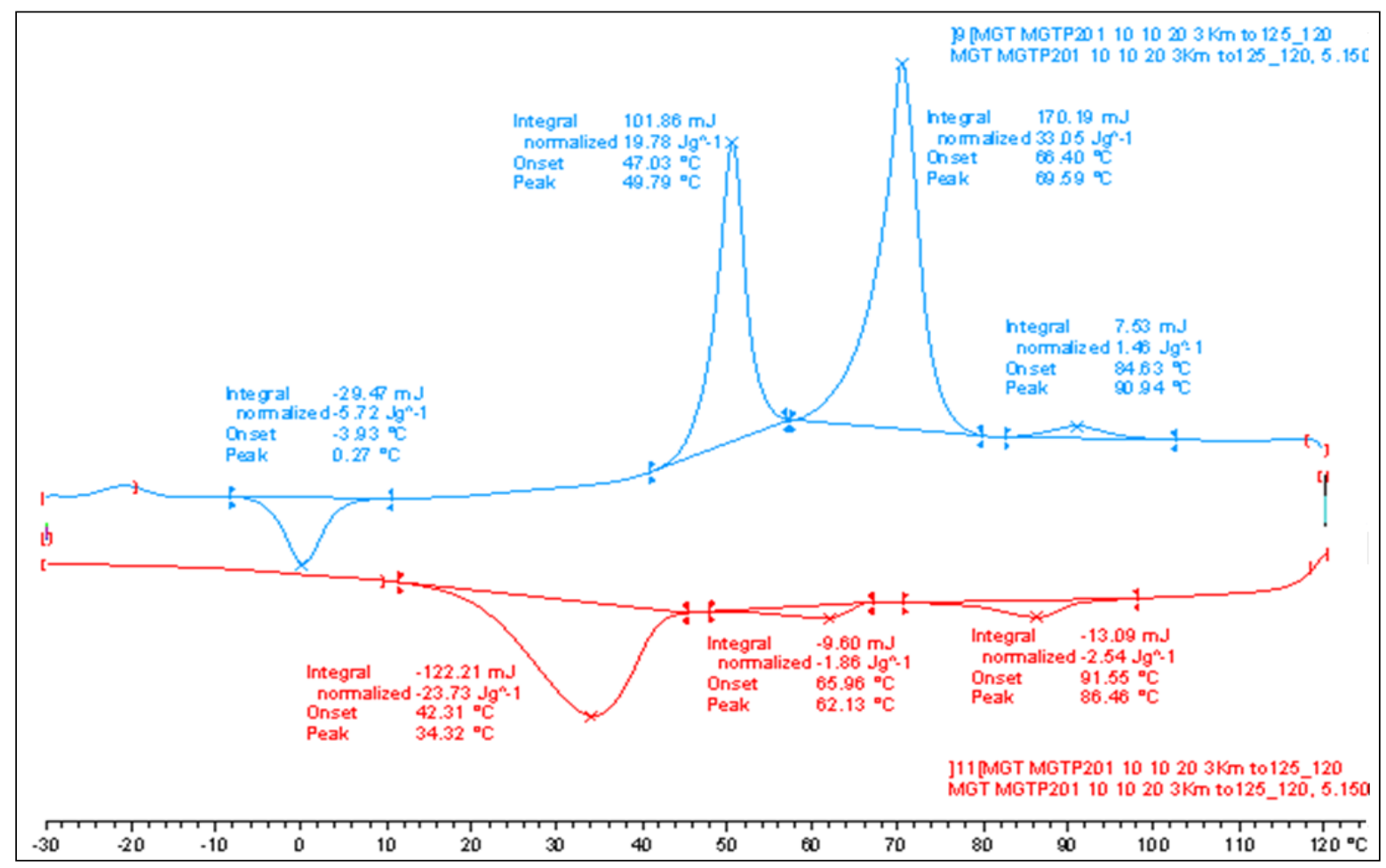

Figure 7. XRD patterns of an aligned sample of the mixture, MGTP201, in the magnetic field on cooling. (a,b) XRD patterns of the nematic phase at $77{ }^{\circ} \mathrm{C}$ : (a) original pattern; (b) the same XRD pattern, but the intensity of the isotropic liquid is subtracted; (c,d) XRD patterns of the $\mathrm{N}_{\mathrm{x}}$ at $50{ }^{\circ} \mathrm{C}$ : (c) original pattern; (d) the same XRD pattern, but the intensity of the isotropic liquid is subtracted.

\section{High temperature}

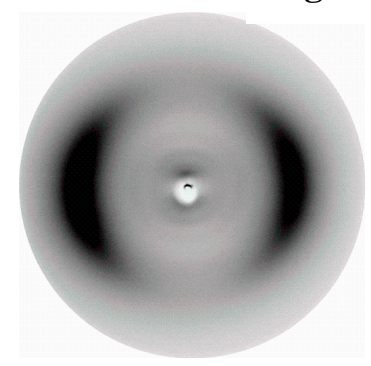

(a)

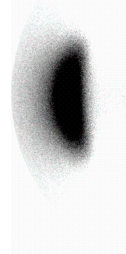

(b)

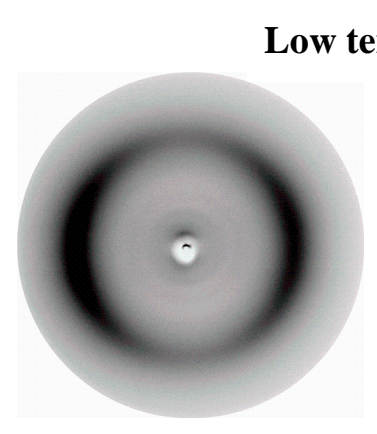

(c)

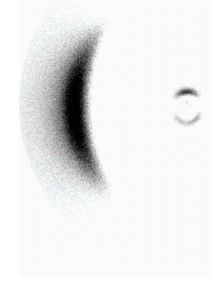

(d) 
Figure 8. Textures of the nematic phase of 2 between untreated glasses observed between crossed polarizers.

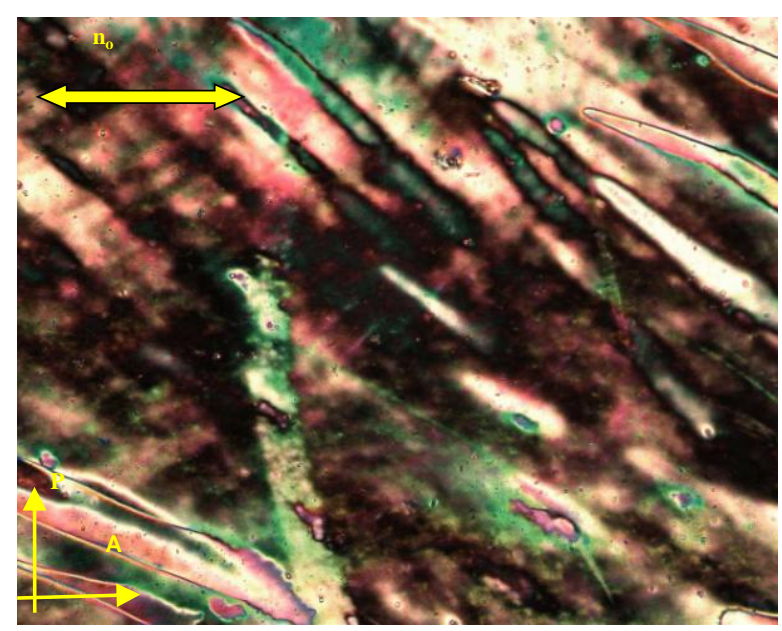

DSC measurements were conducted with different heating and cooling rates on samples of Compound 2. The transition temperatures and the corresponding enthalpy values of Compound $\mathbf{2}$ taken from the heating and cooling DSC scans recorded at $10 \mathrm{~K} / \mathrm{min}$, shown in Figure 9, are given below.

Figure 9. DSC studies $(10 \mathrm{~K} / \mathrm{min}$ ) of Compound 2, the first heating and cooling scan. The values are taken from the second heating and cooling scans. The transitions are: $\mathrm{N} 107.6$ (2.22) Iso $\left({ }^{\circ} \mathrm{C}\right)$; Iso $106.2(-2.03) \mathrm{N}-14.0 \mathrm{Tg}\left({ }^{\circ} \mathrm{C}\right)$; the numbers in brackets are the transition enthalpies in $\mathrm{J} \cdot \mathrm{g}^{-1}$.

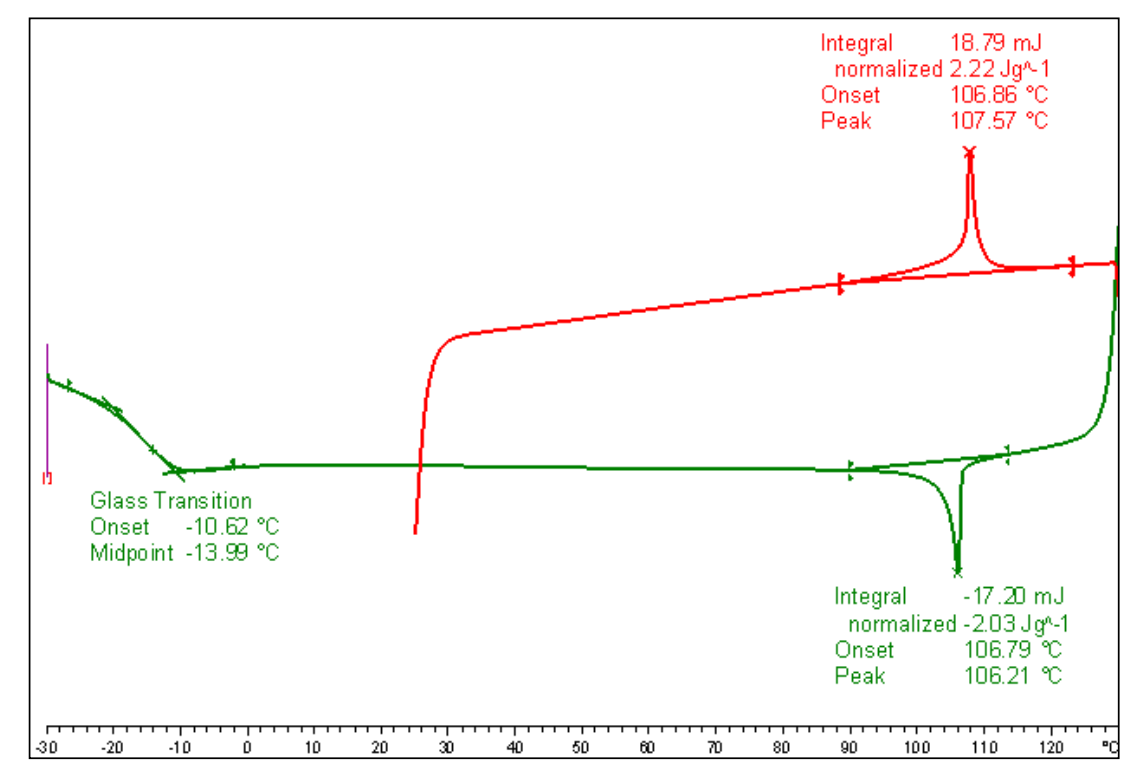

An investigation of the selected composition of the binary mixtures (w/w) of Material 2 with a positive dielectric anisotropy with the cyanobiphenyl dimer, CB_C9_CB, at concentrations of 15\% and $25 \%(\mathrm{w} / \mathrm{w})$ evidenced that all of the compositions exhibit a nematic phase behaviour. The mesophase types and transition temperatures for these mixtures are given in Table 2. The mesophases of the mixtures were characterized by their optical defect textures, calorimetric studies and by X-ray 
investigations. No additional layer- structured mesophases are induced in the mixed phase region of this binary systems, i.e., only nematic phases could be found.

It is noted that the recorded systems show monotropic $\mathrm{N}_{\mathrm{x}}$ phase behaviour; or in other words, the $\mathrm{N}_{\mathrm{x}}$ phase is a meta-stable phase, which can be obtained upon cooling from the nematic $(\mathrm{N})$ phase. As a representative example of the mesophase behaviour, the results for the binary mixture, MGTP208, with 15\% (w/w) 2 in CB_C9_CB will be described in more detail. The POM studies and the calorimetric investigations evidenced the existence of an $\mathrm{N}-\mathrm{N}_{\mathrm{x}}$ phase sequence with textural and structural features similar to the pure cyanobiphenyl dimer, CB_C9_CB. The high-temperature phase could be easily identified as a nematic phase by its characteristic texture; a typical schlieren texture is shown in Figure 10a. At the phase transition to the $\mathrm{N}_{\mathrm{X}}$ phase, a fan-shaped texture develops. This is shown in Figure 10b. The sheared texture, shown in Figure 10c, contains non-specific features and some oily streaks.

Table 2. Transition temperatures of the binary mixtures (w/w) of $\mathbf{2}$ with the dimer, CB_C9_CB, taken from the first DSC heating and cooling scans $\left(10 \mathrm{~K} \cdot \mathrm{min}^{-1}\right)$.

\begin{tabular}{|c|c|c|c|}
\hline $\begin{array}{c}\text { Binary } \\
\text { mixtures }\end{array}$ & $\begin{array}{c}2 \\
\%(w / w)\end{array}$ & $\begin{array}{c}\text { CB_C9_CB } \\
\%(w / w)\end{array}$ & $\begin{array}{c}\text { Transitions temperatures } \\
\left({ }^{\circ} \mathbf{C}\right)\end{array}$ \\
\hline CB_C9_CB & 0 & 100 & $\mathrm{Cr} 85.2 \mathrm{~N}_{\mathrm{x}} 107.3 \mathrm{~N} 124.2$ Iso; Iso $122.4 \mathrm{~N} 104.9 \mathrm{~N}_{\mathrm{x}} 40.5 \mathrm{Cr}$ \\
\hline MGTP208 & 15 & 85 & Cr $86.7 \mathrm{~N} 112.0$ Iso; Iso $110.3 \mathrm{~N} 88.1 \mathrm{~N}_{\mathrm{X}} 41.4 \mathrm{Cr}$ \\
\hline MGTP209 & 25 & 75 & Cr 86.7 N 108.8 Iso; Iso $106.4 \mathrm{~N} 83.7 \mathrm{~N}_{\mathrm{X}} 41.2 \mathrm{Cr}$ \\
\hline $\mathbf{2}^{\mathrm{a}}$ & 100 & 0 & $\mathrm{Tg}-8.8 \mathrm{~N} 107.6 \mathrm{Iso}$; Iso $106.3 \mathrm{~N}-14 \mathrm{Tg}$ \\
\hline
\end{tabular}

${ }^{\text {a }}$ Values for the heating scan are taken from the second heating scan.

Figure 10. Textures of the MGTP208 (15\% (w/w) 2 in $85 \%$ (w/w) CB_C9_CB) between untreated glass slides, observed in the same region upon cooling between crossed polarizers: (a) schlieren texture in the high-temperature nematic $\mathrm{N}$ phase at $100{ }^{\circ} \mathrm{C}$; (b) fan-like texture of the low-temperature $\mathrm{N}_{\mathrm{x}}$ phase at $70{ }^{\circ} \mathrm{C}$ and (c) sheared texture of the low-temperature $\mathrm{N}_{\mathrm{x}}$ phase at $70{ }^{\circ} \mathrm{C}$.

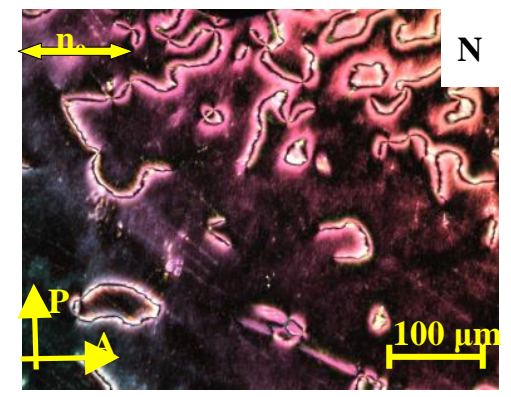

(a)

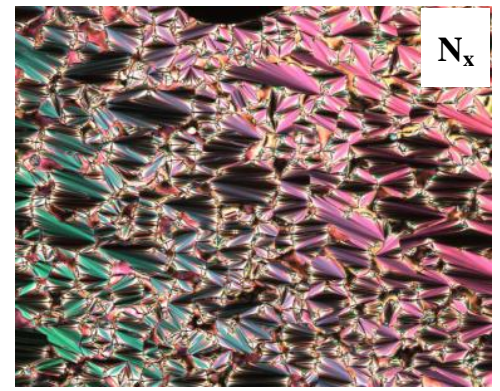

(b)

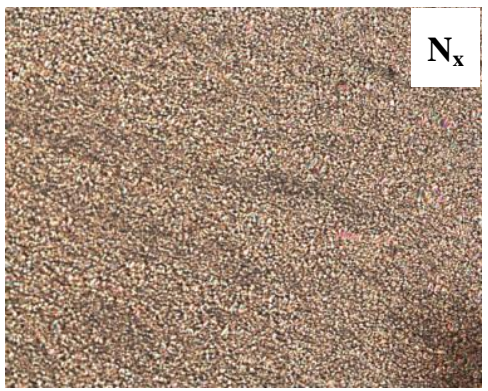

(c)

DSC measurements were conducted at different heating and cooling rates of samples of the binary mixture, MGTP208. The transition temperatures and the corresponding enthalpy values of the binary mixture, MGTP208, taken from the heating and cooling DSC scan collected at $10 \mathrm{~K} / \mathrm{min}$, are shown in Figure 11 below. The lowering of the isotropisation temperature of the composition of $\sim 12{ }^{\circ} \mathrm{C}$, when compared to pure CB_C9_CB is lower than found for the comparable mixture with the monomeric system, 1. 
Figure 11. DSC studies $(10 \mathrm{~K} / \mathrm{min})$ of the binary mixture, MGTP208 $(15 \%(\mathrm{w} / \mathrm{w}) 2$ in 85\% CB_C9_CB); the values are taken from the first heating and cooling scans. Cr 86.7 (49.74) N 112.0 (1.96) Iso $\left({ }^{\circ} \mathrm{C}\right)$; Iso $110.3(-2.22) \mathrm{N} 88.1(-2.35) \mathrm{N}_{\mathrm{x}} 41.4(-41.44)$ $\mathrm{Cr}\left({ }^{\circ} \mathrm{C}\right)$; the numbers in brackets are the transition enthalpies in $\mathrm{J} \cdot \mathrm{g}^{-1}$.

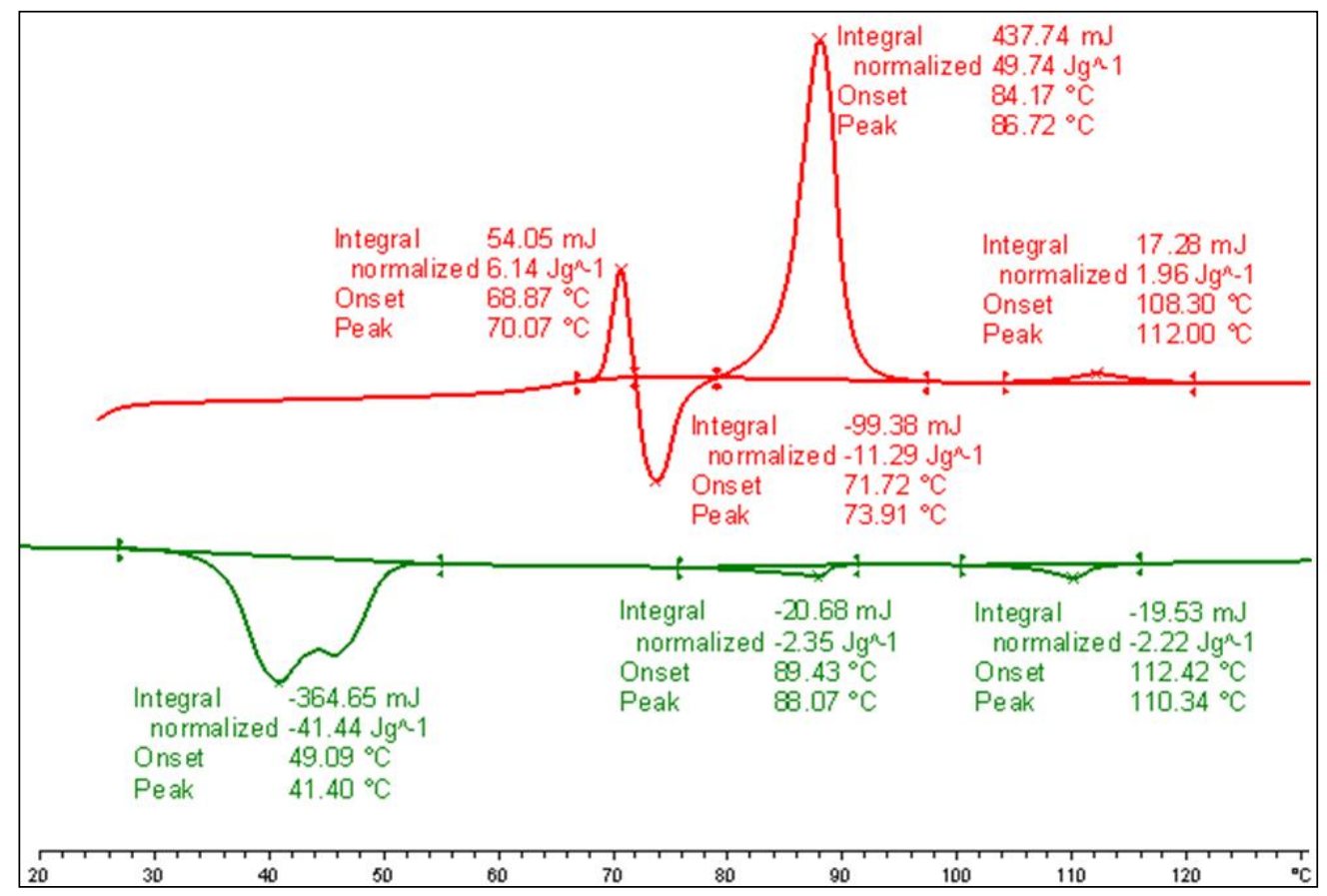

X-ray measurements were performed whilst applying a magnetic field of about $0.5 \mathrm{~T}$ applied to orient the samples of the composition, MGTP208. The results confirm the presence of two nematic phases. The X-ray patterns in the high-temperature nematic state show the known features of the XRD patterns of the nematic phase of the pure cyanobiphenyl dimer, i.e., diffuse crescent-like scattering on the meridian in the small angle region (parallel to the orienting magnetic field) and diffuse crescent-like scattering on the equator in the wide-angle region. A diffractogram of the composition, MGTP208, recorded at $97{ }^{\circ} \mathrm{C}$ is shown in Figure 12a,b. Similar to the pure cyanobiphenyl dimer, this pattern does not change significantly at the phase transition to the low-temperature $\mathrm{N}_{X}$ phase. The diffractogram recorded at $70{ }^{\circ} \mathrm{C}$ is shown in Figure $12 \mathrm{c}$,d. There is no indication of a transition to a smectic phase, even though the textural features, such as a fan-shaped texture and/or polygonal textures, occur.

Based on the results on the monomeric and dimeric systems, the miscibility of CB_C9_CB with liquid crystal gold nanoparticles was explored. These initial experiments suggested that a concentration of $\sim 15 \%$ of the gold nanoparticle system in CB_C9_CB might still allow for $\mathrm{N}_{\mathrm{x}}$ phase formation. As the initial LC gold nanoparticle system, Material $\mathbf{3}$ was selected. For $\mathbf{3}$, the gold particles have a diameter of $\sim 3.3 \mathrm{~nm}$; the chemical synthesis, liquid crystal phase behaviour and plasmonic properties have been reported elsewhere [22]. The results for the mixture, MGTP212 (15\% 3 in $85 \%$ CB_C9_CB w/w) will be described. The POM studies and the calorimetric investigations evidenced the existence of the phase sequence, $\mathrm{N}-\mathrm{N}_{\mathrm{x}}$, with textural and structural features similar to the pure cyanobiphenyl dimer, CB_C9_CB. The high-temperature phase could be easily identified as a nematic phase by its characteristic texture. At the phase transition to the $\mathrm{N}_{\mathrm{x}}$ phase, a fine structured fan-shaped texture develops, as shown in Figure 13a,b. The sheared texture contains non-specific features, a 
small-scale fan-shaped texture and homeotropically oriented regions and some oily streaks, shown in Figure 13c.

Figure 12. XRD patterns of an aligned sample of mixture MGTP208 in the magnetic field upon cooling. (a,b) XRD patterns of the nematic phase at $97{ }^{\circ} \mathrm{C}$ : (a) original pattern; (b) the same XRD pattern, but the intensity of the isotropic liquid is subtracted. (c,d) XRD patterns of the $\mathrm{N}_{\mathrm{x}}$ at $70{ }^{\circ} \mathrm{C}$ : (c) original pattern; (d) the same XRD pattern, but the intensity of the isotropic liquid is subtracted.

High temperature

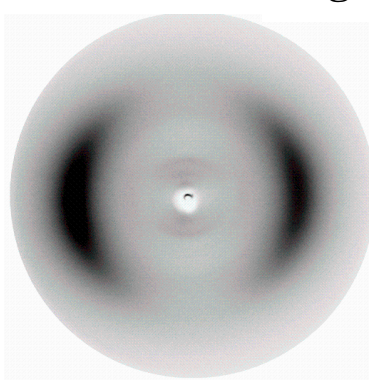

(a)

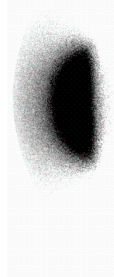

(b)

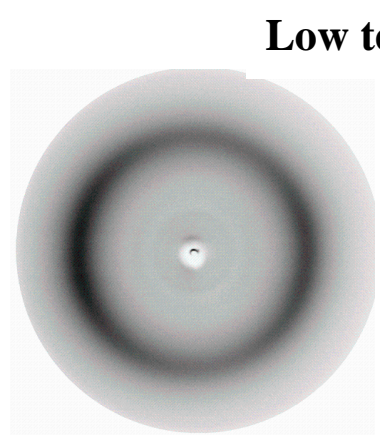

(c)

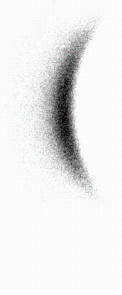

(d)

Figure 13. Textures of the binary mixture, MGTP212 (15\% (w/w) 3 in 85\% CB_C9_CB), at $U=0 \mathrm{~V}$ between untreated glasses observed in the same region upon cooling between crossed polarizers: (a) schlieren texture in the high-temperature nematic $\mathrm{N}$ phase at $113{ }^{\circ} \mathrm{C}$; (b) fan-like texture of the low-temperature $\mathrm{N}_{\mathrm{x}}$ phase at $100{ }^{\circ} \mathrm{C}$ and (c) sheared texture of the low-temperature $\mathrm{N}_{\mathrm{x}}$ phase at $84{ }^{\circ} \mathrm{C}$.

(a)
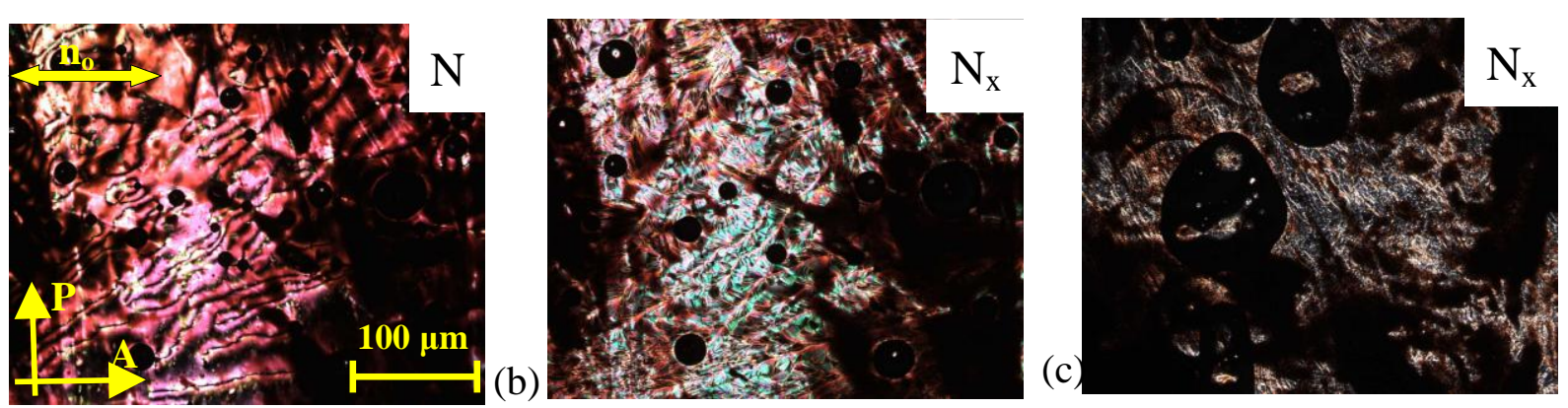

DSC measurements were conducted at different heating and cooling rates of samples of the binary mixture, MGTP212 $(15 \%(\mathrm{w} / \mathrm{w}) 3$ in 85\% CB_C9_CB). The transition temperatures and the corresponding enthalpy values of the binary mixture, MGTP212, taken from heating and cooling DSC scans $(10 \mathrm{~K} / \mathrm{min})$ are shown in Figure 14 . A crucial feature is that only a very small reduction of the isotropisation temperature occurs, when compared to pure CB_C9_CB and the stabilisation of the $\mathrm{N}_{\mathrm{x}}$ phase formation, which is enantiotropic in this system can be observed.

$\mathrm{X}$-ray measurements were performed whilst applying a magnetic field of about $0.5 \mathrm{~T}$ to orient the samples of the binary mixture, MGTP212 (15\% (w/w) 3 in 85\% CB_C9_CB). The results confirm the presence of two nematic phases. The X-ray patterns in the high-temperature nematic state show the known features of the XRD patterns of the nematic phases of the pure cyanobiphenyl based dimers, i.e., diffuse crescent-like scattering on the meridian in the small angle region (parallel to the orienting 
magnetic field) and diffuse crescent-like scattering on the equator in the wide-angle region collected at $112{ }^{\circ} \mathrm{C}$ and shown in Figure 15a. Similar to the dimer containing cyanobiphenyl units, this pattern does not change significantly at the phase transition to the low-temperature $\mathrm{N}_{X}$ phase. A representative diffraction pattern, collected at $80{ }^{\circ} \mathrm{C}$, is shown in Figure $15 \mathrm{~b}$. Small angle intensities occur. $\theta$-scans of the diffraction pattern in the $\mathrm{N}$ and $\mathrm{N}_{\mathrm{x}}$ and the isotropic phases are shown in Figure 15c. As the small angle intensities persist in the isotropic phase, they are attributed to the average distance of the gold nanoparticles dispersed in the mixture. The distribution of the wide-angle scattering along $\chi$ in the $\mathrm{N}$ and $\mathrm{N}_{\mathrm{x}}$ phases (plotted are the recorded intensities $v s . \chi\left(15^{\circ}-25^{\circ} 2 \theta\right)$ ) is shown Figure $15 \mathrm{~d}$ for data recorded at $112{ }^{\circ} \mathrm{C}$ and $80^{\circ} \mathrm{C}$. To enhance the visibility of the signal, the raw data was divided by the data collected in the isotropic phase at $135{ }^{\circ} \mathrm{C}$. It is noticeable that the macroscopic orientation in the $\mathrm{N}_{\mathrm{x}}$ phase is much larger than in the $\mathrm{N}$ phase, where there is hardly any increased orientation when compared to the isotropic phase. Beyond the small angle intensity, attributed to the gold nanoparticles, there is no indication of a transition to a smectic phase, even though the POM textural features, such as the fan-shaped texture, could suggest such a smectic-like structure formation.

Figure 14. DSC studies $(10 \mathrm{~K} / \mathrm{min})$ of the MGTP212; the values are taken from the first heating and cooling scans. Cr 85.6 (49.05) Nx 105.7 (1.19) N 122.2 (2.90) Iso $\left({ }^{\circ} \mathrm{C}\right)$; Iso $121.2(-3.02) \mathrm{N} 105.5(-1.47) \mathrm{Nx} 30.3(-21.38) \mathrm{Cr}$; the numbers in brackets are the

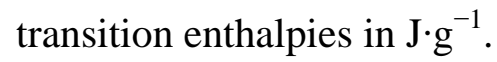

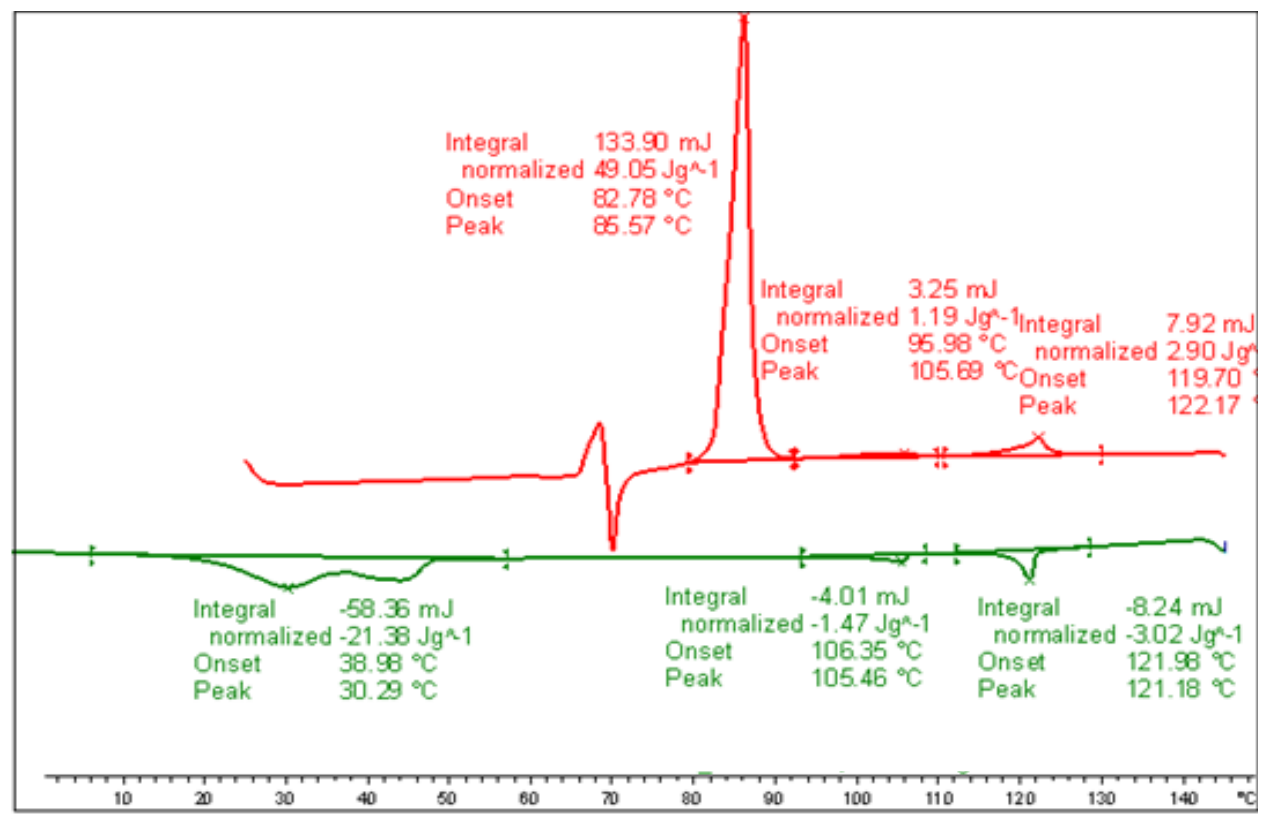

Based on these results, the investigations were extended to the gold nanoparticle system, $\mathbf{4}$, where the synthesis and the liquid crystal properties have been reported elsewhere [24]. The NP system, 4, is characterized by particle diameters of $\sim 10 \mathrm{~nm}$; the LC groups are attached by an amino group to the gold nanoparticles; the spacer linking LC groups and nanoparticles contain a siloxane group, introduced in order to lower the glass transition temperatures and the viscosity of the system. Based on the previous results and for systematic reasons, a high concentration of CB_C9_CB in the mixture was targeted. The results of the investigation of the mixture, MGTP211 (15\% 4 in CB_C9_CB w/w), will be described. The POM studies and the calorimetric investigations evidenced the existence of an 
$\mathrm{N}-\mathrm{N}_{\mathrm{x}}$ phase sequence with textural and structural features similar to the pure cyanobiphenyl dimer, CB_C9_CB. The high-temperature phase could be easily identified as a nematic phase by its characteristic texture. At the phase transition to the $\mathrm{N}_{\mathrm{X}}$ phase, a fine structured fan-shaped texture develops, shown in Figure 16a,b. The sheared texture contains a non-specific features, a small-scale fan-shaped texture and homeotropically oriented regions and some oily streaks, shown in Figure 16c.

Figure 15. XRD patterns of an aligned sample of the mixture MGTP212 in a magnetic field upon cooling: (a) $\mathrm{N}$ phase at $112{ }^{\circ} \mathrm{C}$ (the insert subtracted intensities were recorded in the isotropic phase); (b) $\mathrm{N}_{\mathrm{x}}$ at $80{ }^{\circ} \mathrm{C}$ (the insert subtracted intensities of the isotropic phase); (c) $\theta$-scan of the diffraction pattern in the $\mathrm{N}$ and $\mathrm{N}_{\mathrm{x}}$ phases; SAXS: $d=0.470 \mathrm{~nm}$ $\left(112{ }^{\circ} \mathrm{C}\right), d=0.453 \mathrm{~nm}\left(80{ }^{\circ} \mathrm{C}\right)$; (d) distribution of the wide-angle scattering along $\chi$ in the $\mathrm{N}$ and $\mathrm{N}_{\mathrm{x}}$ phases; intensity vs. $\chi\left(15^{\circ}-25^{\circ} 2 \theta\right)$.

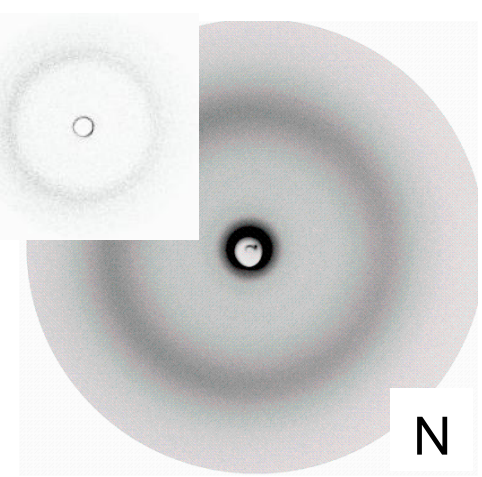

(a)

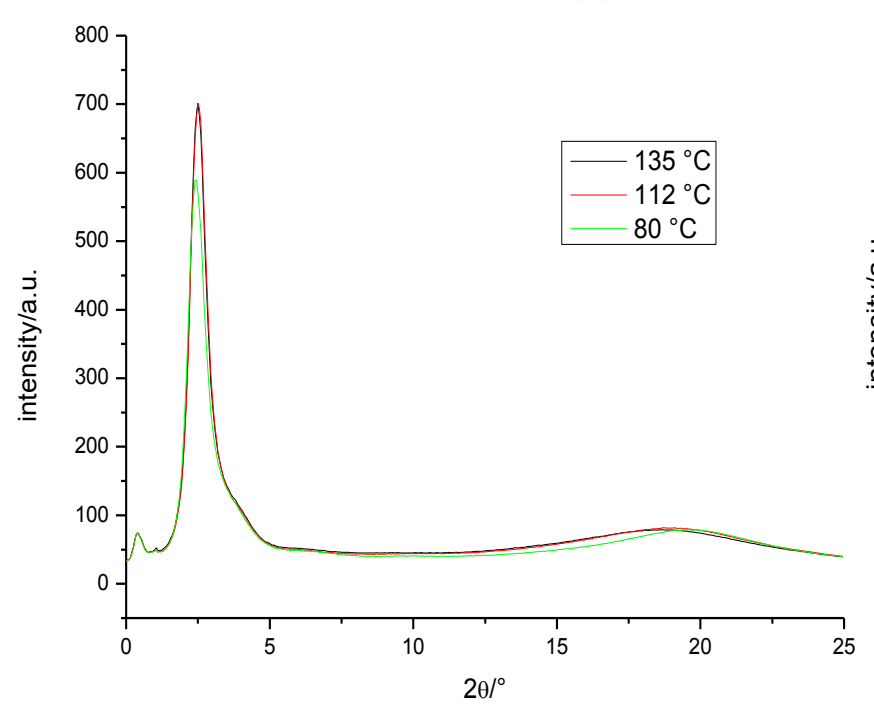

(c)

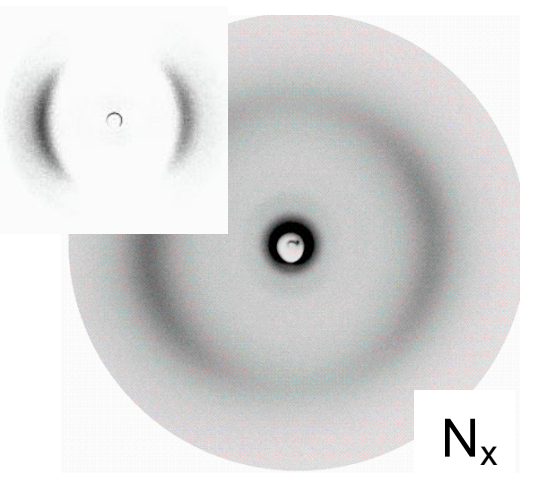

(b)

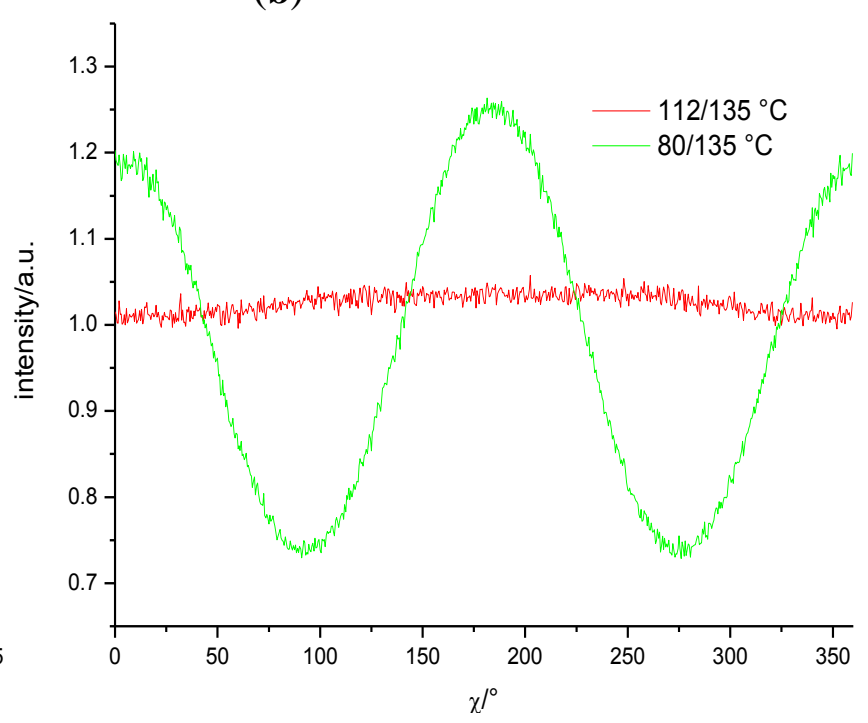

(d)

DSC measurements were conducted at varying heating and cooling rates of the samples of the binary mixture, MGTP211 (15\% (w/w) 4 in 85\% (w/w) CB_C9_CB). The transition temperatures and the corresponding enthalpy values taken from the heating and cooling DSC scans $(10 \mathrm{~K} / \mathrm{min})$ are shown in Figure 17. The surprising result is that the $\mathrm{N}_{\mathrm{x}}$ phase formation has been stabilized; the composition with a $15 \%(\mathrm{w} / \mathrm{w})$ addition of $\mathbf{4}$ forms an enantiotropic $\mathrm{N}_{\mathrm{x}}$ phase, stable upon heating up to $104.7^{\circ} \mathrm{C}$. 
Figure 16. Textures of the binary mixture, MGTP211 (15\% (w/w) 4 in 85\% CB_C9_CB), between untreated glasses observed in the same region upon cooling between crossed polarizers: (a) schlieren texture in the high-temperature nematic $\mathrm{N}$ phase at $113{ }^{\circ} \mathrm{C}$; (b) fan-like texture of the low-temperature $\mathrm{N}_{\mathrm{x}}$ phase at $100{ }^{\circ} \mathrm{C}$; and (c) sheared texture of the low-temperature $\mathrm{N}_{\mathrm{x}}$ phase at $84{ }^{\circ} \mathrm{C}$.

(a)

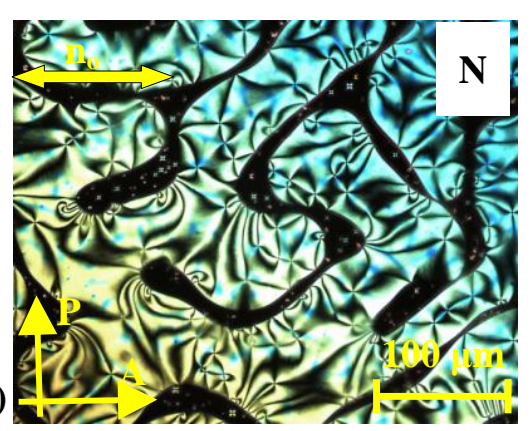

(b)

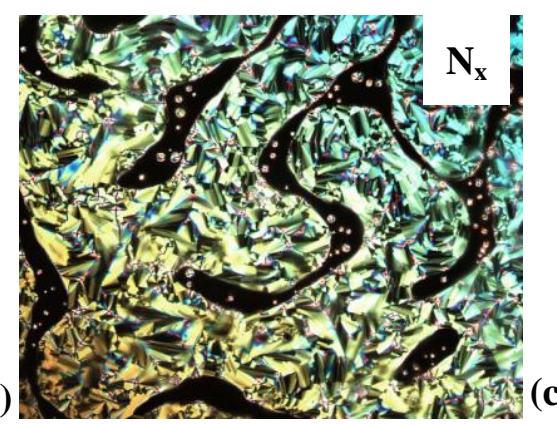

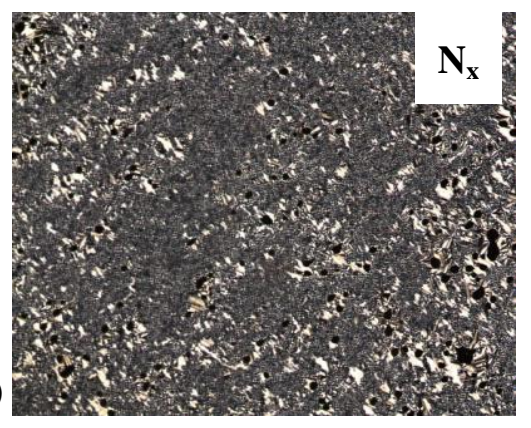

Figure 17. DSC studies (10 K/min) of the mixture, MGTP211; the values are taken from the first heating and cooling scans. Heating: Cr 85.4 (29.3) Nx 104.7 (1.42) N 121.2 (2.20) Iso. Numbers in brackets, transition enthalpies $\mathrm{J}^{-g^{-1}}$. Cooling: Iso $114.2(-2.29) \mathrm{N} 102.7$ $(-1.63) \mathrm{N}_{\mathrm{x}} 47.1(-39.96) \mathrm{Cr}$; the numbers in brackets are the transition enthalpies in $\mathrm{J} \cdot \mathrm{g}^{-1}$.

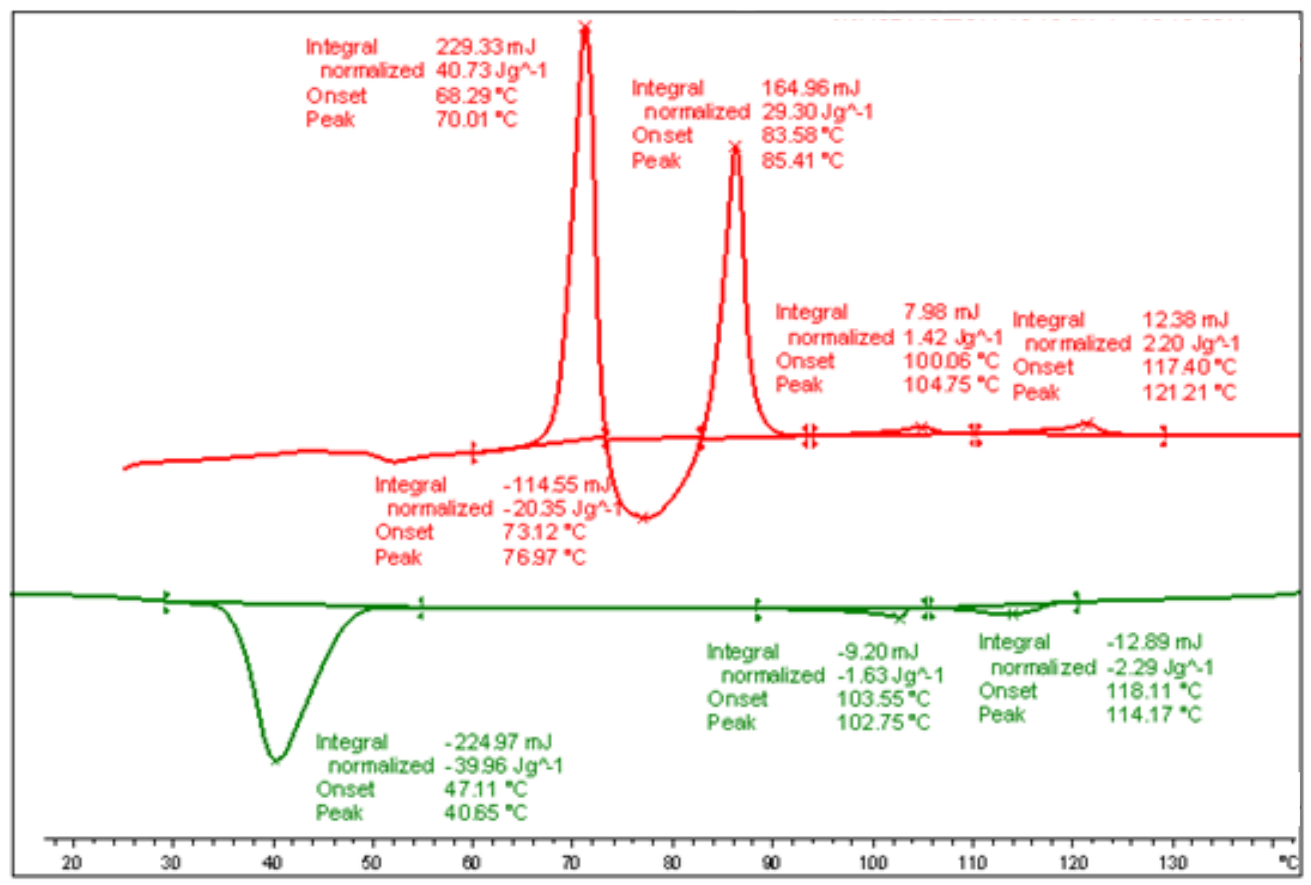

$\mathrm{X}$-ray measurements were performed whilst applying a magnetic field of about $0.5 \mathrm{~T}$ on oriented samples of the binary mixture, MGTP211. The results show that the composition can be aligned by a relatively weak magnetic field. The results confirm the presence of two nematic phases. The X-ray patterns in the high-temperature nematic state show the known features of the XRD patterns of the nematic phases of the pure cyanobiphenyl or terphenyl dimers, i.e., diffuse crescent-like scattering on the meridian in the small angle region (parallel to the orienting magnetic field) and diffuse crescent-like scattering on the equator in the wide-angle region, shown in Figure 18a; the data were recorded at $108{ }^{\circ} \mathrm{C}$. Similar to a pure dimer containing cyanobiphenyl units, this pattern does not change 
significantly at the phase transition to the low-temperature $\mathrm{N}_{\mathrm{X}}$ phase; an example is in Figure $18 \mathrm{~b}$ of the data recorded at $80{ }^{\circ} \mathrm{C}$. Figure $18 \mathrm{c}$ shows the distribution of the wide-angle scattering along $\chi$ in the $\mathrm{N}$ phase at $108{ }^{\circ} \mathrm{C}$ and $\mathrm{N}_{\mathrm{x}}$ phases at $80{ }^{\circ} \mathrm{C}$ (plot: recorded intensity vs. $\chi\left(15^{\circ}-25^{\circ} 2 \theta\right)$; the values are divided by the data recorded in the isotropic phase at $135^{\circ} \mathrm{C}$, for better contrast). Though there seems to be some sharpening of the intensities at $\sim 90^{\circ}$, parallel to the external magnetic field, at $80{ }^{\circ} \mathrm{C}$, when compared to the nematic phase, overall, the differences are minimal. The $\theta$-scan of the diffraction patterns in the $\mathrm{N}$ and $\mathrm{N}_{\mathrm{x}}$ phases at 108 and $80{ }^{\circ} \mathrm{C}$ show no strong small angle intensities; the data is very similar to the pure CB_C9_CB.

Figure 18. XRD patterns of an aligned sample of the mixtures, MGTP211, in a magnetic field (vertical) on cooling: (a) $\mathrm{N}$ phase at $108{ }^{\circ} \mathrm{C}$; (b) $\mathrm{N}_{\mathrm{x}}$ at $80{ }^{\circ} \mathrm{C}$; (c) distribution of the wide-angle scattering along $\chi$ in the $\mathrm{N}$ and $\mathrm{N}_{\mathrm{x}}$ phases; intensity vs. $\chi\left(15^{\circ}-25^{\circ} 2 \theta\right)$; (d) $\theta$-scan of the diffraction pattern in the $\mathrm{N}$ and $\mathrm{N}_{\mathrm{x}}$ phases; SAXS: $d=1.29 \mathrm{~nm}\left(108{ }^{\circ} \mathrm{C}\right)$, $d=1.29 \mathrm{~nm}\left(80^{\circ} \mathrm{C}\right)$.

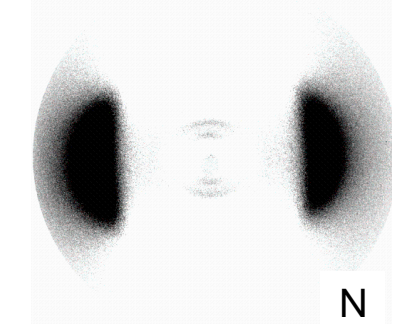

(a)

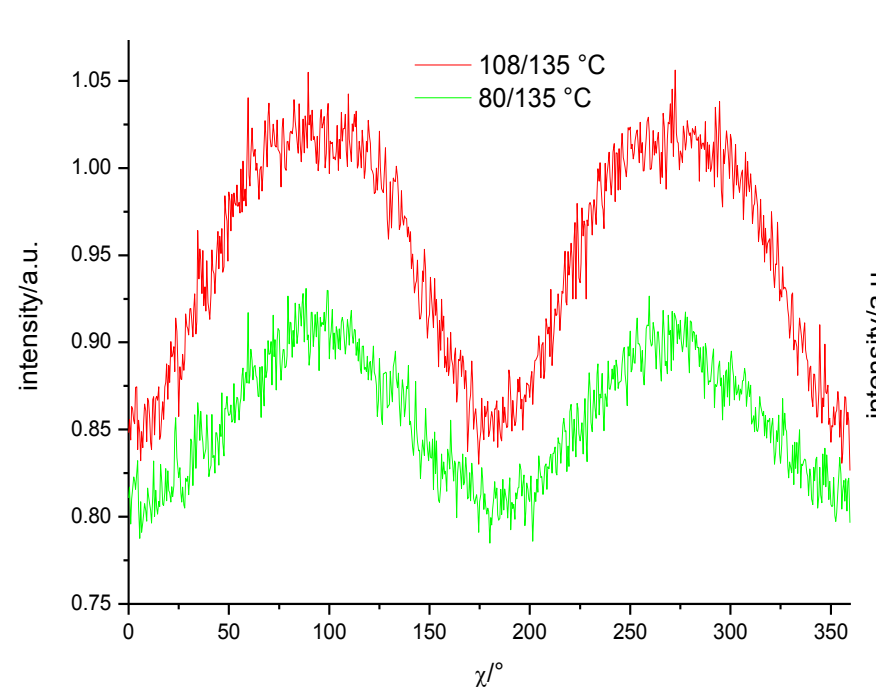

(c)

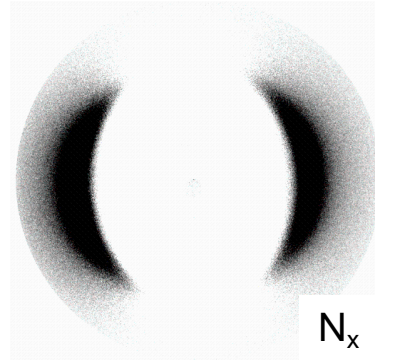

(b)

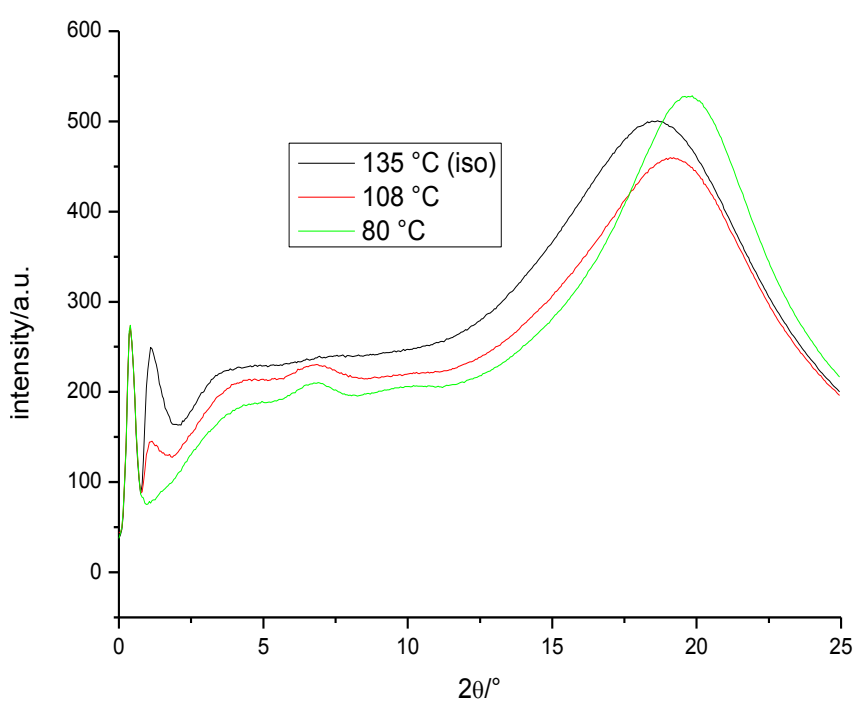

(d)

The absence of the reflections for average distances of the large gold particles is attributed to their size. They are anticipated to be at smaller angles than what can be recorded with the equipment available. There is no indication of a transition to a smectic phase, even though the textural features, such as the fan-shaped texture and polygonal textures, could suggest a smectic-like structure, indicative of the limited use of the analysis of optical defect textures for the identification of the $\mathrm{N}_{\mathrm{x}}$ phase formation. 


\section{Experimental Section}

The synthesis of the materials has been reported elsewhere. X-ray diffraction experiments were performed on an MAR345 diffractometer with a 2D image plate detector ( $\mathrm{CuK} \alpha$ radiation, graphite monochromator, $\lambda=1.54 \AA$ ) (MAR Research, Hamburg, Germany). The samples were heated in the presence of a magnetic field using a home-built capillary furnace. Phase transitions were determined using a Mettler DSC822e stage (Mettler Toledo Intl. Inc. Switzerland) DSC with STARe software calibrated with indium in a nitrogen atmosphere calibrated against an indium standard $\left(156.6{ }^{\circ} \mathrm{C}\right.$; $28.45 \mathrm{~J} \cdot \mathrm{g}^{-1}$; reported transition temperatures are the peak of the endotherm). Polarising microscopy studies were carried out using an Olympus BX51 polarising microscope (Olympus Corp., Tokyo, Japan). The microscope was equipped with a Mettler-Toledo FP900 heating stage (Mettler Toledo Intl. Inc., Greifensee, Switzerland).

\section{Conclusions}

In a systematic study, the dimer system, CB_C9_CB, was mixed with a laterally functionalized monomer, a structurally related laterally connected dimer system and LC nanoparticles, where the diameter of the gold particles was varied between $\sim 3.3$ and $\sim 10 \mathrm{~nm}$. In all the investigated materials, a nematic-nematic phase transition could be introduced, though at varying concentrations of the components. The compositions were characterised by POM, DSC and XRD investigations. The results show that it is possible to construct stable liquid crystal nanocomposites with materials having a metallic plasmonic response. It was found that, surprisingly, the $\mathrm{N}_{\mathrm{x}}$ phase formation was not destabilized in mixtures with liquid crystalline gold nanoparticles; however, destabilization of the $\mathrm{N}_{\mathrm{x}}$ phase formation occurred when mixing with a conventional laterally functionalized nematic monomer and a structurally related dimer. These results open up investigations of systems that combine the advantageous properties of nematic-nematic systems with those that have the properties of metallic nanoparticles.

\section{Acknowledgements}

The work was carried out through funding by the Engineering and Physical Sciences Research Council (EPSRC) grants EP/J004480/1 and EP/G030006/1 and the EU FP7 contracts, 216025 and 228455. Mass spectroscopic analysis of the organic materials by the national mass spectrometry facility in Swansea is acknowledged.

\section{Author Contributions}

Maria-Gabriela Tamba carried out the miscibility studies and the LC characterisation of the materials investigated. Chih Hao Yu, Bai Jia Tang, Christopher P. Schubert and Christopher Welch were responsible for the synthesis of the NP-LCs. Alexandra Kohlmeier, Christopher Welch and Maria-Gabriela Tamba were responsible for the synthesis of the liquid crystals. Georg H. Mehl directed the research and wrote the manuscript with input from Maria-Gabriela Tamba. 


\section{Conflicts of Interest}

The authors declare no conflict of interest.

\section{References}

1. Panov, V.; Nagaraj, M.; Vij, J.K.; Panarin, Y.P.; Kohlmeier, A.; Tamba, M.G.; Lewis, R.A.; Mehl, G.H. Spontaneous periodic deformations in nonchiral planar-aligned bimesogens with a nematic-nematic transition and a negative elastic constant. Phys Rev. Lett. 2010, 105, 167801, doi:10.1103/PhysRevLett.105.167801.

2. Chen, D.; Porada, J.H.; Hooper, J.B.; Klittnick, A.; Shen, Y.; Tuchband, M.R.; Korblova, E.; Bedrov, D.; Walba, D.M.; Clark, N.A.; et al. Chiral heliconical ground state of nanoscale pitch in a nematic liquid crystal of achiral molecular dimmers. Proc. Natl. Acad. Sci. USA 2013, 110, 15931-15936.

3. Cestari, M.; Diez-Berart, S.; Dunmur, D.A.; Ferrarini, A.; de la Fuente, M.R.; Jackson, D.J.B.; Lopez, D.O.; Luckhurst, G.R.; Perez-Jubindo, M.A.; Richardson, R.M.; et al. Phase behavior and properties of the liquid-crystal dimer 1",7"-bis(4-cyanobiphenyl-4'-yl) heptane: A twist-bend nematic liquid crystal. Phys. Rev. E 2011, 84, 031704, doi:10.1103/PhysRevE.84.031704.

4. Beguin, L.; Emsley, J.W.; Lelli, M.; Lesage, A.; Luckhurst, G.R.; Timimi, B.A.; Zimmermann, H. The chirality of a twist-bend nematic phase identified by NMR spectroscopy. J. Phys. Chem. B 2012, 116, 7940-7951.

5. Meyer, C.; Luckhurst, G.R.; Dozov, I. Flexoelectrically driven electroclinic effect in the twist-bend nematic phase of achiral molecules with bent shapes. Phys. Rev. Lett. 2013, 111, 067801, doi:10.1103/PhysRevLett.111.067801.

6. Borshch, V.; Kim, Y.-K.; Xiang, J.; Gao, M.; Jákli, A.; Panov, V.P.; Vij, J.K.; Imrie, C.T.; Tamba, M.G.; Mehl, G.H.; Lavrentovich, O.D. Nematic twist-bend phase with nanoscale modulation of molecular orientation. Nat. Commun. 2013, 4, 2635, doi:10.1038/ncomms3635.

7. Burnell, E.; Kohlmeier, A.; Tamba, M.G.; Mehl, G.H.; Dong, R. Solute NMR study of a bimesogenic liquid crystal with two nematic phases. Chem. Phys. Lett. 2012, 552, 44-48.

8. Tripathi, C.S.P.; Losada-Perez, P.; Leys, J.; Kohlmeier, A.; Tamba, M.-G.; Mehl, G.H.; Glorieux, C. The nematic-nematic phase transition in a liquid crystal dimer $\mathrm{CBC} 9 \mathrm{CB}$ and mixtures with 5CB: A high-resolution adiabatic scanning calorimetric study. Phys. Rev. E 2011, 84, 041707, doi:10.1103/PhysRevE.84.041707.

9. Panov, V.P.; Balachandran, R.; Nagaraj, M.; Vij, J.K.; Tamba, M.G.; Kohlmeier, A.; Mehl, G.H. Microsecond linear optical response in the unusual nematic phase of achiral. Appl. Phys. Lett. 2011, 99, 261903, doi:10.1063/1.3671996.

10. Hoffmann, A.; Vanakaras, A.G.; Kohlmeier, A.; Mehl, G.H.; Photinos, D.J. On the structure of the Nx phase of symmetric dimmers. 2014, arXiv:1401.5445v1.

11. Keith, C.; Lehmann, A.; Baumeister, U.; Prehm, M.; Tschierske, C. Nematic phases of bent-core mesogens. Soft Matter 2010, 6, 1704-1721.

12. Zep, A.; Aya, S.; Aihara, K.; Ema, K.; Pociecha, D.; Madrak, K.; Bernatowicz, P.; Takezoe, H.; Gorecka, E. Multiple nematic phases observed in chiral mesogenic dimmers. J. Mater. Chem. C 2013, $1,46-49$. 
13. Tschierske, C.; Photinos, D.J. Biaxial nematic phases. J. Mater. Chem. 2010, 20, 4263-4294.

14. Sharma, A.; Worden, M.; Hegmann, T. Nanoparticle-Promoted thermal stabilization of room temperature cholesteric blue phase mixtures. Ferroeletrics 2012, 431, 154-163.

15. Pendry, J.B. A chiral route to negative refraction. Science 2004, 306, 1353-1355.

16. Menzel, C.; Helgert, C.; Rockstuhl, C.; Kley, E.B.; Pertsch, A.T.T.; Leder, F. Asymmetric transmission of linearly polarized light at optical metamaterials. Phys. Rev. Lett. 2010, 104, 253902, doi:10.1103/PhysRevLett.104.253902.

17. Donnio, B. Liquid-Crystalline metallodendrimers. Inorg. Chim. Acta 2014, 409, 53-57.

18. Nealon, G.L.; Greget, R.; Dominguez, C.; Nagy, Z.T.; Guillon, D.; Gallani, J.J.; Donnio, B. Liquid-Crystalline nanoparticles: Hybrid design and mesophase structures. Beilstein J. Org. Chem. 2012, 8, 349-370.

19. Stamatoiu, O.; Mizaei, J.; Feng, X.; Hegmann, T. Liquid crystals: Materials design and self assembly. In Topics in Current Chemistry; Tschierkse, C., Ed.; Springer Verlag: Berlin, Germany, 2012; Volume 318, pp. 331-393.

20. Balachandran, R.; Panov, P.; Vij, J.K.; Kocot, A.; Tamba, M.G.; Mehl, G.H. Elastic properties of bimesogenic liquid crystals. Liq. Cryst. 2013, 40, 681-688.

21. Cseh, L.; Mehl, G.H. The design and the investigation of room temperature thermotropic nematic gold nanoparticles. J. Am. Chem. Soc. 2006, 128, 13377-133786.

22. Zeng, X.; Cseh, L.; Fowler, A.; MacDonald, J.E.; Mehl, G.H.; Ungar, G. 3-D ordered gold strings by coating nanoparticles with mesogens. Adv. Mater. 2009, 21, 1746-1750.

23. Dintinger, J.; Tang, B.J.; Zeng, X.; Liu, F.; Kienzler, T.; Mehl, G.H.; Ungar, G.; Rockstuhl, C.; Scharf, T. A self organized anisotropic liquid crystal-plasmonic metamaterial. Adv. Mater. 2013, 25, 1999-2004.

24. Yu, C.H.; Schubert, C.; Tang, B.J.; Welch, C.; Tamba, M.G.; Mehl, G.H. Design, synthesis and characterisation of mesogenic amine capped nematic gold nanoparticles with surface enhanced plasmonic resonances. J. Am. Chem. Soc. 2012, 134, 5076-5079.

25. Elsäßer, R.; Mehl, G.H.; Goodby, J.W.; Veith, M. Novel nematic dendrimers based on carbosilazane cores. Angew. Chem. Int. Ed. 2001, 40, 2688-2690.

26. Elsäßer, R.; Mehl, G.H.; Goodby, J.W.; Photinos, D.J. Nematic silsesquixanes-Towards nanocrystals dispersed in a nematic liquid crystal matrix. Chem. Commun. 2000, 851-852.

27. Diez, S.; Dunmur, D.A.; de la Fuente, M.R.; Karahaliou, P.K.; Mehl, G.H.; Meyer, T.; Jubindo, M.A.P.; Photinos, D.J. Dielectric studies of a laterally-linked siloxane ester dimer. Liq. Cryst. 2003, 30, 1021-1030.

(C) 2014 by the authors; licensee MDPI, Basel, Switzerland. This article is an open access article distributed under the terms and conditions of the Creative Commons Attribution license (http://creativecommons.org/licenses/by/3.0/). 